\title{
Waardekaarten van: Haisborough, Hammond \& Winterton, North Norfolk Sandbanks \& Saturn Reef
}

Auteur(s): Niels Hintzen

Publicatiedatum: 09-02-2017

Dit onderzoek is uitgevoerd door Wageningen Marine Research in opdracht van en gefinancierd door het Ministerie van Economische Zaken, in het kader van het Beleidsondersteunend onderzoekthema 'Duurzame visserij' (Basnummer BO-20-010-000-I MARES)

Wageningen Marine Research IJ muiden, februari, 2017

Wageningen Marine Research rapport C009/17 
Niels Hintzen, 2017. Wageningen Marine Research Wageningen UR (University \& Research centre), Wageningen Marine Research rapport C009/17. 18 blz.;

Keywords: Waardekaarten, Engelse kust, Visserij.

Opdrachtgever: Ministerie van EZ

T.a.v.: Evelien Ranshuysen

Bezuidenhoutseweg 73

2595 AC, Den Haag

BAS code -BO-20-010-000-I MARES

Wageningen Marine Research Wageningen UR is ISO 9001:2008 gecertificeerd.

Dit rapport is gratis te downloaden van https://doi.org/10.18174/407718.

Wageningen Marine Research verstrekt geen gedrukte exemplaren van rapporten.

(c) 2016 Wageningen Marine Research Wageningen UR

Wageningen Marine Research, onderdeel van Stichting Wageningen Research KvK nr. 09098104,

IMARES BTW nr. NL 8113.83.696.B16. Code BIC/SWIFT address: RABONL2U IBAN code: NL 73 RABO 0373599285
De Directie van Wageningen Marine Research is niet aansprakelijk voor gevolgschade, noch voor schade welke voortvloeit uit toepassingen van de resultaten van werkzaamheden of andere gegevens verkregen van Wageningen Marine Research opdrachtgever vrijwaart Wageningen Marine Research van aanspraken van derden in verband met deze toepassing.

Dit rapport is vervaardigd op verzoek van de opdrachtgever hierboven aangegeven en is zijn eigendom. Niets uit dit rapport mag weergegeven en/of gepubliceerd worden, gefotokopieerd of op enige andere manier gebruikt worden zonder schriftelijke toestemming van de opdrachtgever. 


\section{Samenvatting}

Langs de Engelse kust staan een aantal gebieden op de UK Natura 2000 agenda voor sluiting voor de Nederlandse demersale vloot. Wageningen Marine Research bestudeerde in hoeverre de Nederlandse vloot actief was in dit gebied en hoe de voorgenomen te sluiten gebieden overlappen met voor de visserij interessante visgronden.

Een grotere opbrengst (factor 3) wordt gehaald uit het North Norfolk Sandbanks \& Saturn Reef gebied (dit is één gebied) ten opzichte van het Haisborough, Hammond and Winterton gebied (dit is ook één gebied). Vooral tong word in dit eerste gebied gevangen terwijl scholvangsten groter zijn in het tweede gebied.

De voornaamste visgronden die interessant zijn voor de Nederlandse sector zijn niet opgenomen in de voorgenomen te sluiten gebieden, waarbij juist voor de visserij interessante delen van de totale zoekgebieden niet aangemerkt zijn als te sluiten gebied. 


\section{$1 \quad$ Inleiding}

Dit rapport is geschreven in opdracht van het ministerie van EZ. WMR is gevraagd om waardekaarten en tabellen te leveren van alle bodemberoerende Nederlandse visserijschepen binnen de gebieden 1) Haisborough, Hammond and Winterton, 2) North Norfolk Sandbanks \& Saturn Reef 


\section{Methoden}

Om tot beantwoording van uw vraag te komen, hebben wij de volgende activiteiten uitgevoerd: Voor de door u aangeleverde bodemberoerende tuigcategorieën (TBB, OTB, OTT, SSC, SDN, PTB, HMD, \& DRB) met Nederlandse schepen zijn de beschikbare logboek gegevens en beschikbare VMS gegevens geselecteerd voor de jaren 2011 tot en met 2014.

Voor de reizen waarvoor zowel logboek als VMS registraties beschikbaar waren zijn gerapporteerde logboek vangsten gekoppeld aan VMS locaties welke op basis van de snelheid zijn gedetermineerd als vissend. Het aandeel logboek gegevens dat niet gekoppeld kon worden was erg klein en daarom is besloten de ruimtelijke verspreiding van de beschikbare VMS leidend te laten zijn voor alle beschikbare logboek gegevens.

De gebruikte methode staat uitgebreid beschreven in Hintzen, N.T.; Coers, A.; Hamon, K. (2013) A collaborative approach to mapping value of fisheries resources in the North Sea (Part 1: Methodology). IJ muiden : IMARES, (Report C001/13) - p. 24.

De VMS registraties op het detail van een "ping" zijn ruimtelijk gekoppeld aan de 3 studiegebieden (figuur 1, gele gebieden). De vangsten per soort $(\mathrm{kg})$ zijn vermenigvuldigd met de marktprijs (euro) van de betreffende maand en jaar. Op basis van de opbrengst is bepaald welke drie soorten de hoogste opbrengst opleverde in de studiegebieden. Deze drie soorten waren schol, tong en tarbot. De opbrengst van de andere soorten is gesommeerd en gepresenteerd als overige soorten.

De totale opbrengst in Euro over alle schepen en alle soorten tezamen is op een ruimtelijke schaal van $0.25 \times 0.125$ graden (1/16 ICES kwadrant) gepresenteerd in figuur 2 - 5 . 


\section{Resultaten}

De analyses vinden plaats op basis van alle VMS en logboek gegevens die zich binnen het gele en blauwe vlak bevinden (Figuur 1 hieronder). Overige gebieden zijn ook potentiele Natura 2000 gebieden langs de Engelse kust maar worden hier verder niet behandeld.

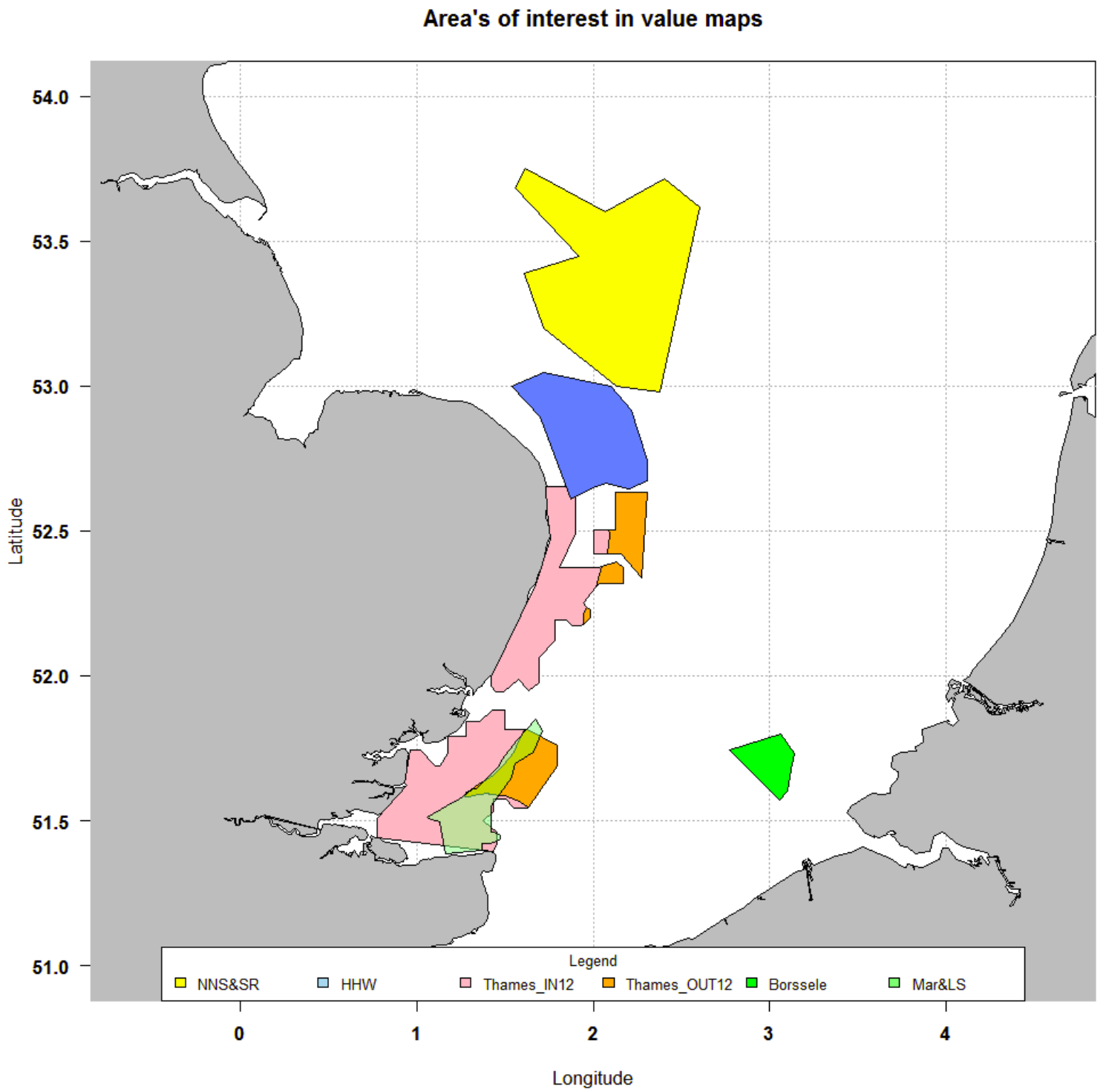

Figuur 1. Presentatie van interessegebieden in geel (North Norfolk and Saturn Reef) en blauw (Haisborough, Hammond \& Winterton).

Voor alle geselecteerde schepen is de totale vangst in 1000xeuro, gemiddeld over de 3 jaar, weergegeven op een resolutie van 1/16 ICES-kwadrant weergegeven. Er worden 2 figuren gepresenteerd, één met de waarde op 1/16de van een ICES-kwadrant (figuur 2) en eenzelfde figuur met VMS pings die als vissend zijn geïdentificeerd er bovenop geprojecteerd (figuur 3 ). 
Valuemap of North Norfolk Sandbanks \& Saturn Reef

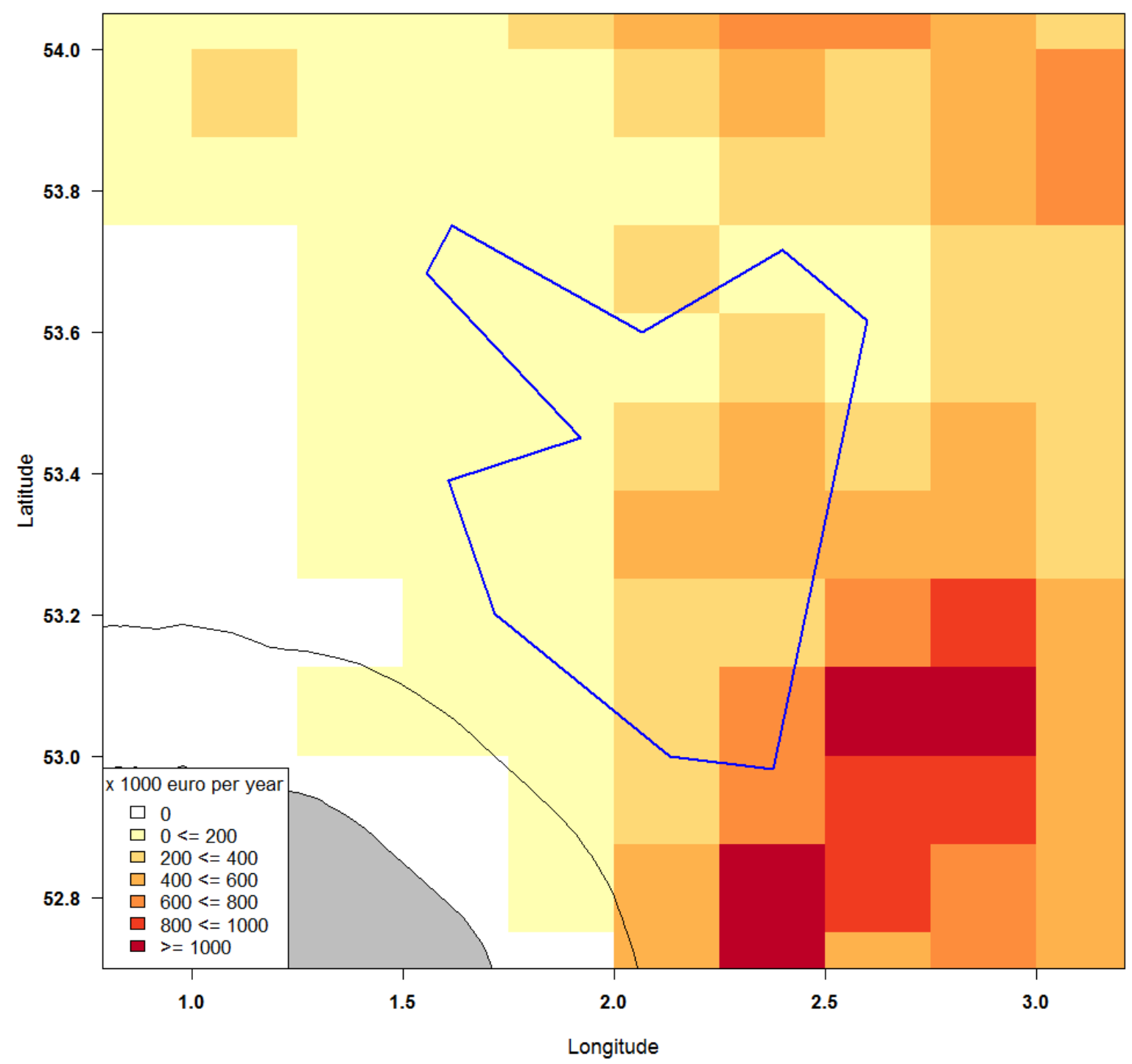

Figuur 2. Presentatie van de gemiddelde waarde van de aanlandingen in het North Norfolk Sandbanks \& Saturn Reef gebied (blauw omkaderd) van alle Nederlandse bodemberoerende tuigen in 2011-2013. De waarde is geschat met behulp van logboek en VMS gegevens. Donkerrode kleur geeft hogere waarde van een gebied aan terwijl wit en lichtgeel lagere waardes representeren. leder vakje komt overeen met $1 / 16^{\text {de }}$ van een ICES vierkant. De kleurcodering komt overeen met ieder vakje. Het UK vaste land is gegeven in grijs en de 12 mijlszone is gegeven als een zwarte lijn. 
Valuemap of North Norfolk Sandbanks \& Saturn Reef

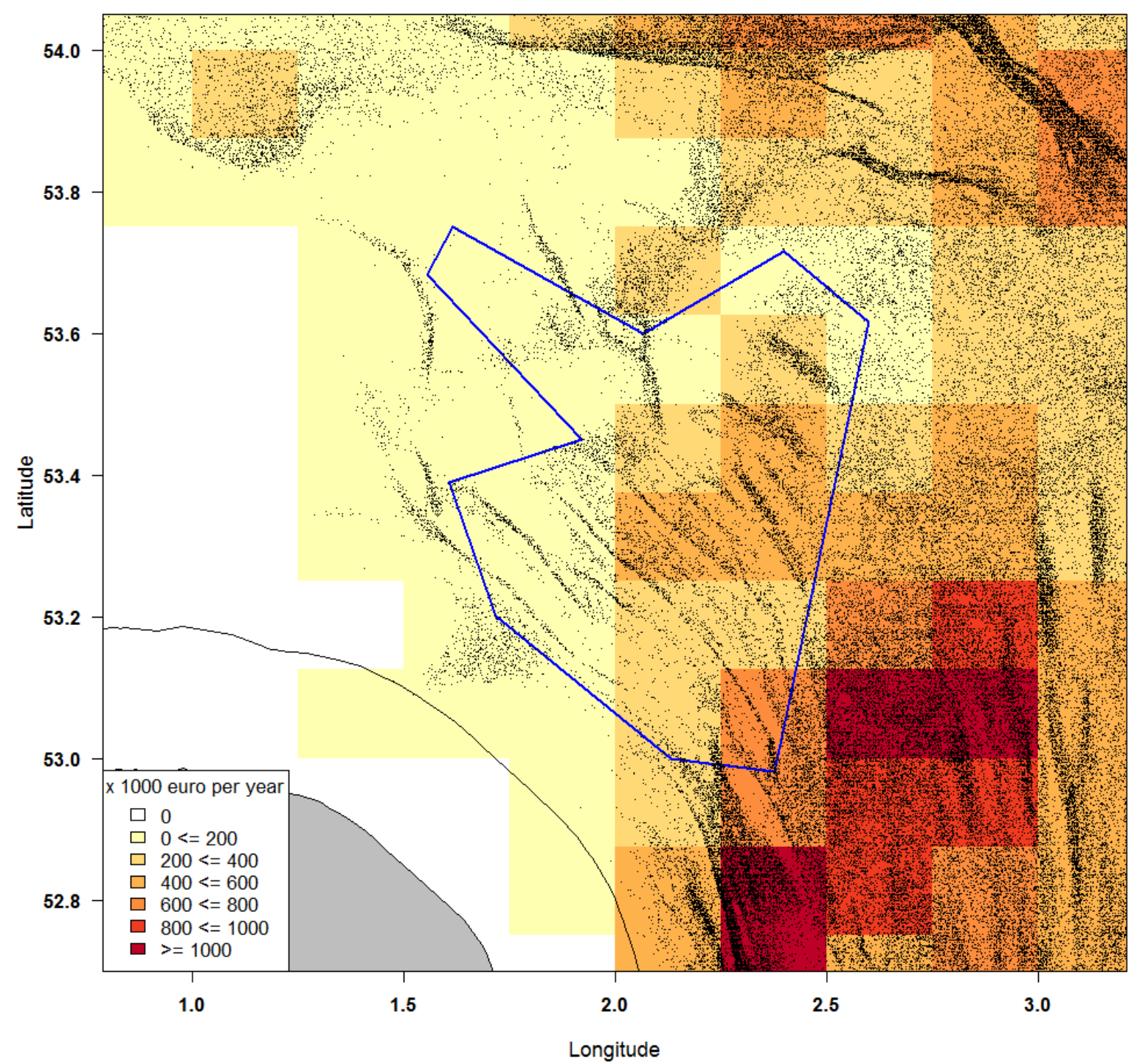

Figuur 3. Presentatie van de gemiddelde waarde van de aanlandingen in het North Norfolk Sandbanks \& Saturn Reef gebied van alle Nederlandse bodemberoerende tuigen in 20112013. De waarde is geschat met behulp van logboek en VMS gegevens. Donkerrode kleur geeft hogere waarde van een gebied aan terwijl wit en lichtgeel lagere waardes representeren. I eder vakje komt overeen met $1 / 16^{\text {de }}$ van een I CES vierkant. De kleurcodering komt overeen met ieder vakje. I eder zwart puntje komt overeen met een VMS registratie waarvan verondersteld wordt dat er vissende activiteit plaats vindt. Het UK vaste land is gegeven in grijs en de 12 mijlszone is gegeven als een zwarte lijn. 
Valuemap of Haisborough, Hammond and Winterton

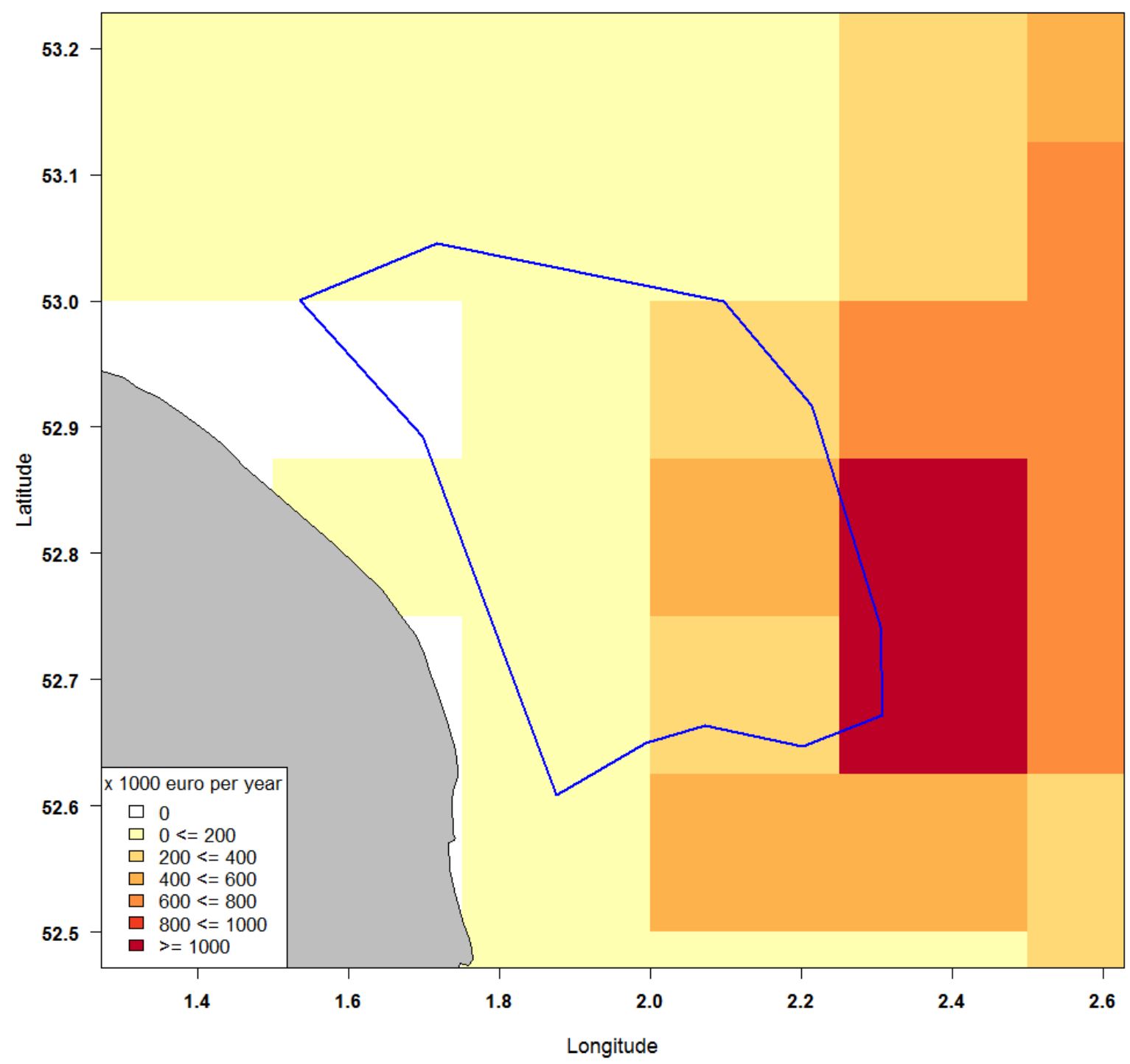

Figuur 4. Presentatie van de gemiddelde waarde van de aanlandingen in het gebied Haisborough, Hammond and Winterton (blauw omkaderd) van alle Nederlandse bodemberoerende tuigen in 2011-2014. De waarde is geschat met behulp van logboek en VMS gegevens. Donkerrode kleur geeft hogere waarde van een gebied aan terwijl wit en lichtgeel lagere waardes representeren. leder vakje komt overeen met $1 / 16^{\text {de }}$ van een ICES vierkant. De kleurcodering komt overeen met ieder vakje. 


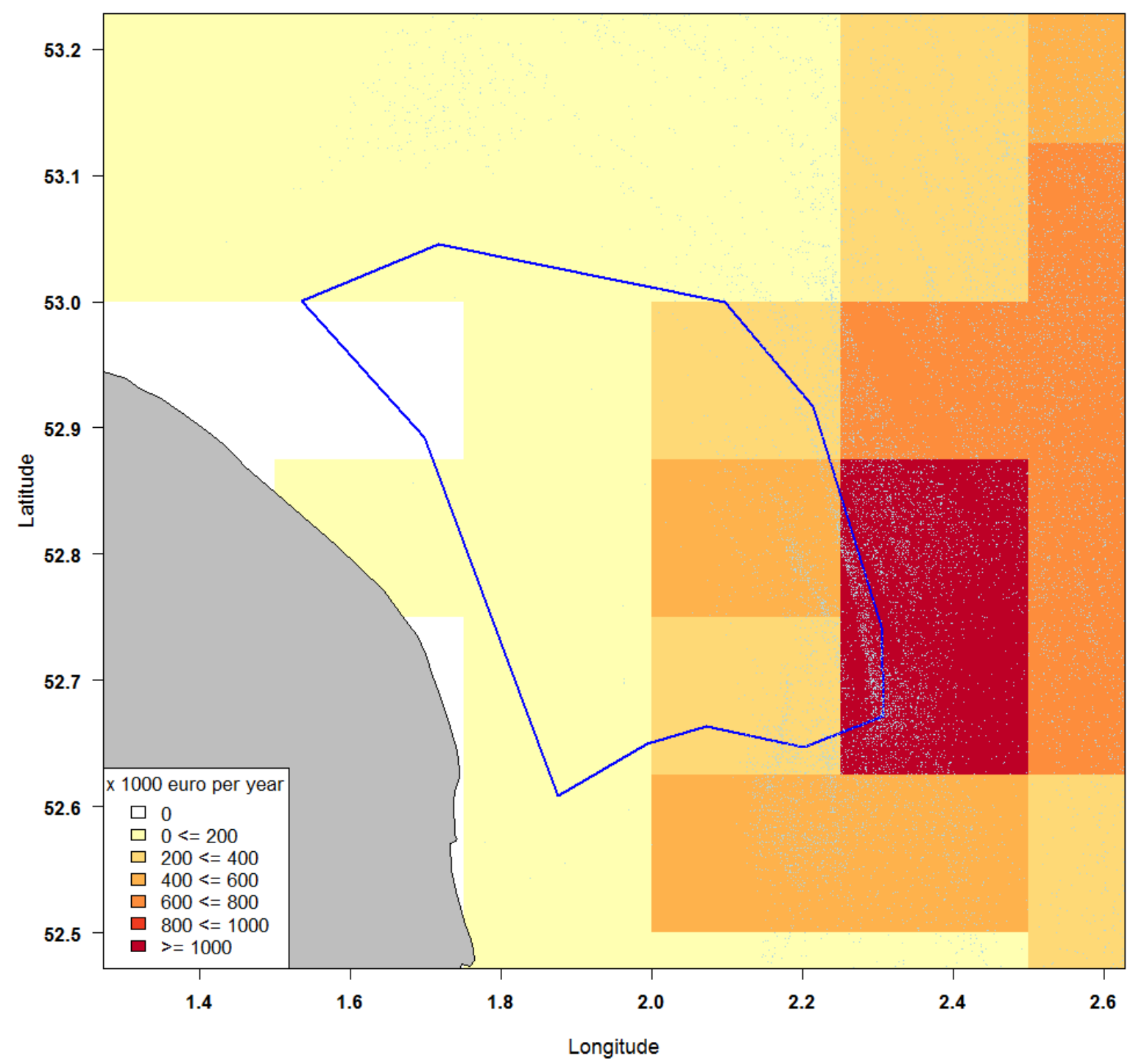

Figuur 5. Presentatie van de gemiddelde waarde van de aanlandingen in het gebied Haisborough, Hammond and Winterton (blauw omkaderd) van alle Nederlandse bodemberoerende tuigen in 2011-2014. De waarde is geschat met behulp van logboek en VMS gegevens. Donkerrode kleur geeft hogere waarde van een gebied aan terwijI wit en lichtgeel lagere waardes representeren. I eder vakje komt overeen met $1 / 16^{\text {de }}$ van een ICES vierkant. De kleurcodering komt overeen met ieder vakje. I eder grijs puntje komt overeen met een VMS registratie waarvan verondersteld wordt dat er vissende activiteit plaats vind. 

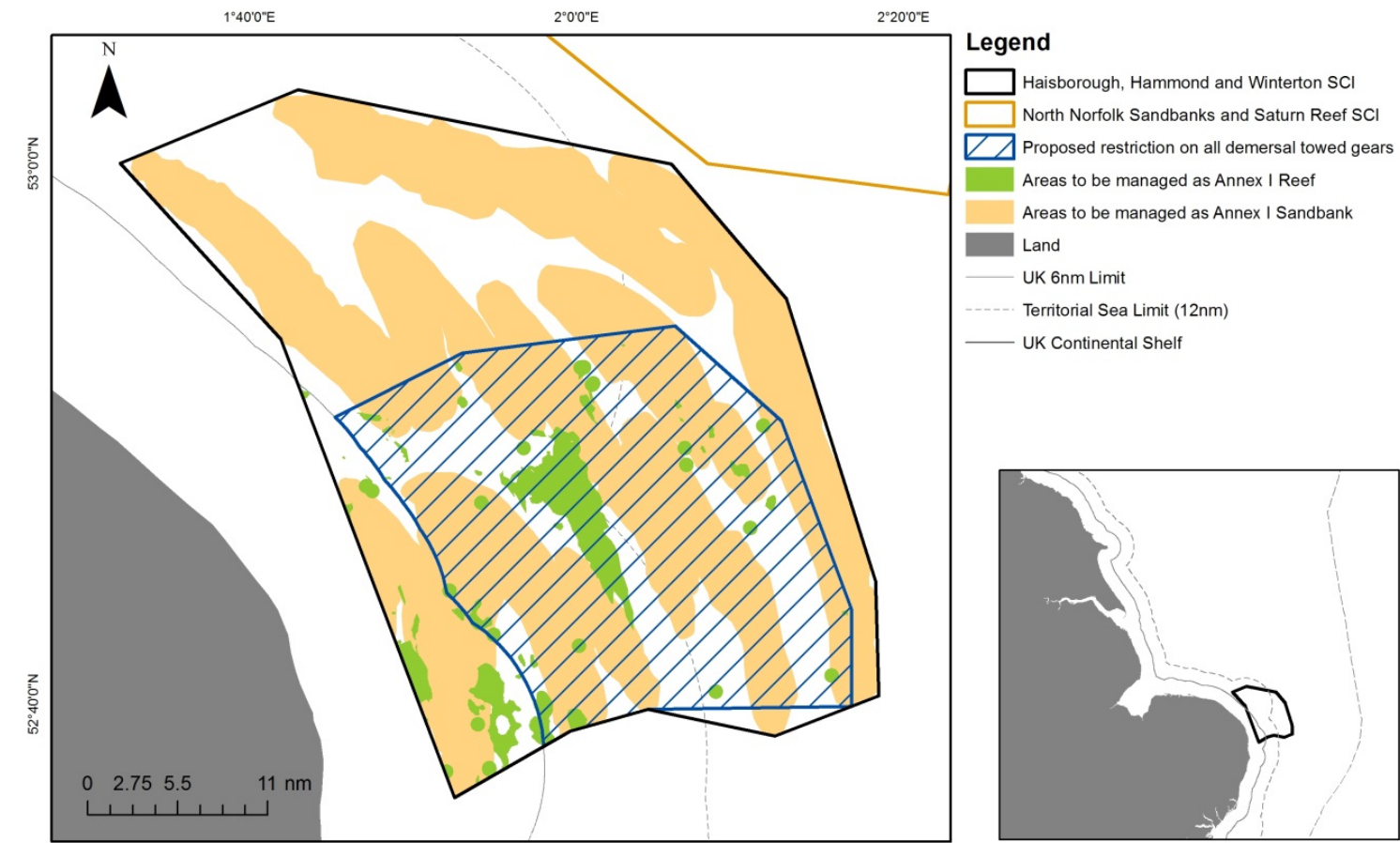

๑ JNCC 2016

UK Territorial Sea Limit. Contains UKHO data ๑ Crown copyright. All rights reserved. The exact limits of the UK Continental shelf are set out in

Combining source layers from UKHO. $\odot$ Crown copyright $\odot$ JNCC. UK Exclusive Economic Zone $\odot$ Crown copyright. The exact limits of the EEZ are set out in The Exclusive Economic Zone Order 2013. World Vector Shoreline ๑ US Defence Mapping Agency. Not to be used for navigation.

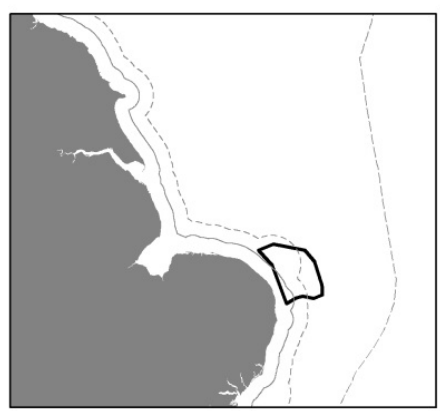

Figuur 6. Voorgenomen te sluiten gebieden Haisborough, Hammond and Winterton
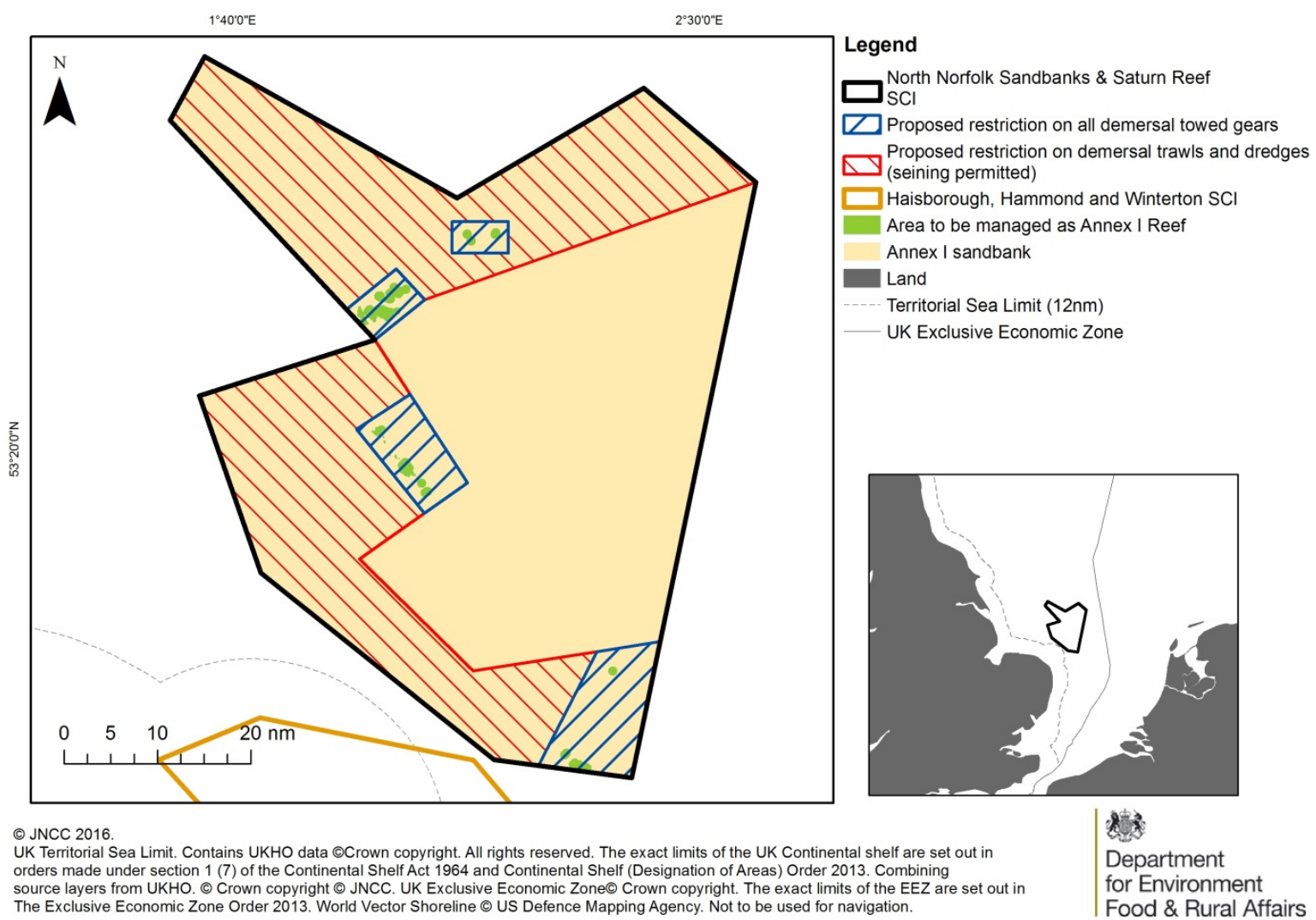

๑) JNCC 2016

UK Territorial Sea Limit. Contains UKHO data @Crown copyright. All rights reserved. The exact limits of the UK Continental shelf are set out in orders made under section 1 (7) of the Continental Shelf Act 1964 and Continental Shelf (Designation of Areas) Order 2013. Combinge The Exclusive Economic Zone Order 2013. World Vector Shoreline $\odot$ US Defence Mapping Agency. Not to be used for navigation.

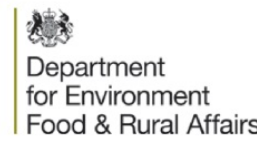

Figuur 7. Voorgenomen te sluiten gebieden North Norfolk Sandbanks \& Saturn Reef 
De opbrengsten in euro per jaar en aanlandingen in kilo's is gegeven in de tabellen hieronder.

Haisborough, Hammond and Winterton

\begin{tabular}{|c|c|c|c|c|c|c|}
\hline & 2011 & 2012 & 2013 & 2014 & Totaal & Gemiddeld \\
\hline \multicolumn{7}{|l|}{ Waarde } \\
\hline Schol & 143,430 & 141,950 & 121,983 & 119,231 & 526,594 & 135,788 \\
\hline Tong & $1,136,615$ & $1,208,042$ & 694,081 & 857,677 & $3,896,415$ & $1,012,913$ \\
\hline Tarbot & 56,850 & 41,827 & 27,386 & 26,068 & 152,132 & 42,021 \\
\hline Rest & 137,780 & 133,556 & 58,856 & 62,779 & 392,971 & 110,064 \\
\hline Total & $1,474,675$ & $1,525,375$ & 902,306 & $1,065,755$ & $4,968,112$ & $1,300,786$ \\
\hline \multicolumn{7}{|l|}{ Kilo } \\
\hline Schol & 96,499 & 96,611 & 89,241 & 88,110 & 370,460 & 94,117 \\
\hline Tong & 100,840 & 129,006 & 80,084 & 96,437 & 406,368 & 103,310 \\
\hline Tarbot & 5,631 & 5,039 & 3,852 & 3,602 & 18,124 & 4,841 \\
\hline Rest & 49,522 & 43,163 & 27,289 & 27,025 & 146,998 & 39,991 \\
\hline Total & 252,491 & 273,818 & 200,466 & 215,175 & 941,950 & 242,258 \\
\hline $\begin{array}{c}\text { Dagen op } \\
\text { zee }\end{array}$ & 190 & 173 & 96 & 109 & 568 & 153 \\
\hline $\begin{array}{c}\text { kW* Dagen } \\
\text { op zee }\end{array}$ & 274,143 & 249,042 & 130,897 & 155,011 & 809,094 & 218,028 \\
\hline
\end{tabular}

North Norfolk Sandbanks \& Saturn Reef

\begin{tabular}{|c|c|c|c|c|c|}
\hline & 2011 & 2012 & 2013 & Totaal & Gemiddeld \\
\hline \multicolumn{6}{|l|}{ Waarde } \\
\hline Schol & 538,608 & 516,260 & 898,842 & $1,953,710$ & 651,237 \\
\hline Tong & $1,608,197$ & $1,299,444$ & $1,865,702$ & $4,773,343$ & $1,591,114$ \\
\hline Tarbot & 164,998 & 207,628 & 322,994 & 695,620 & 231,873 \\
\hline Rest & $1,265,980$ & $2,069,649$ & 313,589 & $3,649,218$ & $1,216,406$ \\
\hline Totaal & $3,577,784$ & $4,092,980$ & $3,401,128$ & $11,071,891$ & $3,690,630$ \\
\hline Schol & 412,385 & 375,960 & 651,782 & $1,440,127$ & 480,042 \\
\hline Tong & 152,852 & 140,900 & 208,024 & 501,777 & 167,259 \\
\hline Tarbot & 18,390 & 28,204 & 44,548 & 91,141 & 30,380 \\
\hline Rest & 455,579 & 634,474 & 55,577 & $1,145,630$ & 381,877 \\
\hline Totaal & $1,039,206$ & $1,179,538$ & 959,931 & $3,178,675$ & $1,059,558$ \\
\hline Dagen op Zee & 415 & 339 & 334 & 1,088 & 363 \\
\hline $\begin{array}{l}\text { kW* Dagen op } \\
\text { Zee }\end{array}$ & 569,246 & 447,548 & 495,133 & $1,511,926$ & 503,975 \\
\hline
\end{tabular}




\section{$4 \quad$ Conclusies en interpretatie}

In het gebied North Norfolk Sandbanks \& Saturn Reef vindt hoofdzakelijk visserij op schol en tong plaats, waarbij tong economisch gezien ongeveer $3 x$ van groter belang is dan schol. Echter, de voornaamste gebieden die interessant zijn voor de visserij liggen buiten het hele gebied van North Norfolk Sandbanks \& Saturn Reef en de visserij vindt nauwelijks plaats in het aangewezen te sluiten gebied (Figuur $6 \& 7$ ). Alleen in de meest zuidelijke hoek van het te sluiten gebied vindt intensievere visserij plaats met een jaarlijkse opbrengst tussen de 600.000 - 800.000 euro per jaar. In de westelijke en noordelijke delen van dit gebied, die ook genoemd zijn als voorgenomen te sluiten gebieden, is de visserijvangst in vergelijking met de aanliggende gebieden laag.

In het gebied Haisborough, Hammond \& Winterton ligt een grotere nadruk op tongvangst en daardoor is er ook een grotere financiële interesse in tong in dit gebied ten opzichte van schol. De opbrengsten uit dit gebied zijn wel een factor 3 kleiner (zie tabel) dan in het North Norfolk Sandbanks \& Saturn Reef gebied. In het gebied vindt weinig visserij plaats, en de voornaamste interessegebieden liggen net ten oosten van dit gebied. Wel ligt een belangrijke rand van het visserijgebied net in het zoekgebied, maar valt dit gebied weer buiten het voorgestelde te sluiten deel als te zien is op figuur 7. In het voorgestelde sluitingsgebied ligt de opbrengst tussen de 200.000 - 600.000 euro per jaar.

De voornaamste visgronden die interessant zijn voor de Nederlandse sector zijn niet opgenomen in de voorgenomen te sluiten gebieden, waarbij juist de voor de visserij interessante delen van de totale zoekgebieden (zoals weergegeven in figuren 1-5) ontweken zijn.

\section{I nterpretatie}

De gerapporteerde waarde van de bestudeerde gebieden reflecteert niet persé de waarde van deze gebieden voor de visserij in de (nabije) toekomst. De waarde van een gebied is hier een combinatie van de aanwezige vis en de geleverde inspanning van de visserij. Als één van deze twee in de toekomst anders wordt, zal ook de waarde veranderen. Wanneer vissers hun activiteit naar andere visgebieden verplaatsen, door bijvoorbeeld het besluit van gebiedssluiting, zal met de methodiek die hier gebruikt is, de waarde van het gebied nul worden. Op te merken hieraan is dat de potentiele waarde voor de visserij berekend zou moeten worden in plaats van de historische waarde; deze methodieken zijn alleen nog niet beschikbaar.

Vissers zullen hun activiteiten verplaatsen naar elders bij sluiting van gebieden. De effecten die deze verplaatsing heeft op vangsten en kosten zijn minder goed bekend. Kennis van verplaatsingsgedrag is daarvoor nodig. Wanneer effecten gering zijn op vlootniveau sluit dat niet uit dat individuele visserij bedrijven substantieel getroffen kunnen worden door sluiting van gebieden op zee. Effecten op vlootniveau zijn naar verwachting minder dan in specifieke gevallen. 


\section{$5 \quad$ Kwaliteitsborging}

Wageningen Marine Research beschikt over een ISO 9001:2008 gecertificeerd kwaliteitsmanagementsysteem (certificaatnummer: 187378-2015-AQ-NLD-RvA). Dit certificaat is geldig tot 15 september 2018. De organisatie is gecertificeerd sinds 27 februari 2001. De certificering is uitgevoerd door DNV Certification B.V.

Het chemisch laboratorium te IJ muiden beschikt over een NEN-EN-ISO/IEC 17025:2005 accreditatie voor testlaboratoria met nummer L097. Deze accreditatie is geldig tot 1 april 2021 en is voor het eerst verleend op 27 maart 1997; deze accreditatie is verleend door de Raad voor Accreditatie. Het chemisch laboratorium heeft hierdoor aangetoond in staat te zijn op technisch bekwame wijze valide resultaten te leveren en te werken volgens de ISO17025 norm. De scope (L097) met de geaccrediteerde analysemethoden is te vinden op de website van de Raad voor Accreditatie (www.rva.nl).

Op grond van deze accreditatie is het kwaliteitskenmerk $\mathrm{Q}$ toegekend aan de resultaten van die componenten die op de scope staan vermeld, mits aan alle kwaliteitseisen is voldaan. Het kwaliteitskenmerk Q staat vermeld in de tabellen met de onderzoeksresultaten. Indien het kwaliteitskenmerk $\mathrm{Q}$ niet staat vermeld is de reden hiervan vermeld.

De kwaliteit van de analysemethoden wordt op verschillende manieren gewaarborgd. De juistheid van de analysemethoden wordt regelmatig getoetst door deelname aan ringonderzoeken waaronder die georganiseerd door QUASIMEME. Indien geen ringonderzoek voorhanden is, wordt een tweede lijnscontrole uitgevoerd. Tevens wordt bij iedere meetserie een eerstelijnscontrole uitgevoerd. Naast de lijnscontroles wordende volgende algemene kwaliteitscontroles uitgevoerd:

- Blanco onderzoek.

- Terugvinding (recovery).

- Interne standaard voor borging opwerkmethode.

- Injectie standard.

- Gevoeligheid.

Bovenstaande controles staan beschreven in Wageningen Marine Research werkvoorschrift ISW 2.10.2.105.

Indien gewenst kunnen gegevens met betrekking tot de prestatiekenmerken van de analysemethoden bij het chemisch laboratorium worden opgevraagd.

Indien sprake is van onbeheerste kwaliteit worden passende maatregelen genomen. 


\section{Literatuur}

Hintzen, N.T.; Coers, A.; Hamon, K. (2013) A collaborative approach to mapping value of fisheries resources in the North Sea (Part 1: Methodology). IJ muiden : IMARES, (Report C001/13) - p. 24 


\section{Verantwoording}

Rapport C009/17

Projectnummer: 4318100133

Dit rapport is met grote zorgvuldigheid tot stand gekomen. De wetenschappelijke kwaliteit is intern getoetst door een collega-onderzoeker en het verantwoordelijk lid van het managementteam van Wageningen Marine Research

Akkoord:

Handtekening:

Datum:

Akkoord:

Handtekening:

Datum:
Ruben Verkempynck

Visserijonderzoeker

10 februari 2017

Drs. J. Asjes

MT lid integratie

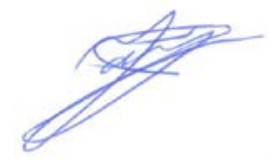

15 februari 2017 
Wageningen Marine Research

T: $+31(0) 317480900$

E: marine-research@wur.nl

www.wur.nl/marine-research

Visitors address

- Ankerpark 271781 AG Den Helder

- Korringaweg 5, 4401 NT Yerseke

- Haringkade 1, 1976 CP IJ muiden
Wageningen Marine Research is the Netherlands research institute established to provide the scientific support that is essential for developing policies and innovation in respect of the marine environment, fishery activities, aquaculture and the maritime sector.

Wageningen University \& Research is specialised in the domain of healthy food and living environment.

\section{The Wageningen Marine Research vision:}

'To explore the potential of marine nature to improve the quality of life.'

The Wageningen Marine Research mission

- To conduct research with the aim of acquiring knowledge and offering advice on the sustainable management and use of marine and coastal areas.

- Wageningen Marine Research is an independent, leading scientific research institute.

Wageningen Marine Research is part of the international knowledge organisation Wageningen UR (University \& Research centre). Within Wageningen UR, nine specialised research institutes of Stichting Wageningen Research (a Foundation) have joined forces with Wageningen University to help answer the most important questions in the domain of healthy food and living environment. 